\title{
Comparison between textured silicone implants and those bonded with expanded polytetrafluoroethylene in rats ${ }^{1}$
}

\author{
Comparação entre implantes de silicone texturizados e esses recobertos por \\ politetrafluoroetileno-expandido em ratos
}

\author{
Douglas Haddad Filho², Deborah K. Zveibel ${ }^{3}$, Nivaldo Alonso ${ }^{4}$, Rolf Gemperli ${ }^{4}$ \\ 1. Research performed at Division of Plastic Surgery, University of Santo Amaro (UNISA) and Division of Plastic Surgery, Department of Surgery, \\ University of São Paulo (USP), Brazil. \\ 2. PhD, Associate Professor, Division of Plastic Surgery, UNISA. São Paulo, Brazil. \\ 3. PhD, Associate Professor, Division of Pathology, School of Medicine of ABC, Santo André, Brazil. \\ 4. PhD, Associate Professor, Division of Plastic Surgery, Department of Surgery, USP, Brazil.
}

\begin{abstract}
Purpose: Comparison of the inflammatory reaction promoted by textured silicone implants and that caused by the implant bonded with e-ptfe. Methods: One-hundred and fifty rats were divided into three equal groups (control, silicone, and bonded e-ptfe). These groups were subdivided into five groups, according to the second operation, i.e., 7,30,60,90 and 180 days. Histology of the peri-implant tissue was analyzed by morphometry with blood count (neutrophilos, lymphocytes, macrophages, fibroblasts and capillaries). Results: Comparison of subgroups 7,30,60,90, 180 days: - neutrophils: silicone: > in subgroup 7 days; bonded e-ptfe: > in subgroups 7 and 30 days; - lymphocytes: silicone: > in subgroup 7 and 180 days; bonded e-ptfe: > in subgroup 180 days; - macrophages: silicone: > in subgroup 7 and 60 days; bonded e-ptfe: > in subgroup 7,30 and 60 days; fibroblasts: silicone: > in subgroup 30 and 60 days;- vascular volume: silicone: in subgroup 7, 60 and 90 days; bonded e-ptfe: > in subgroup 7 days. Comparison of groups: neutrophils : 7 days: > in silicone and bonded e-ptfe; 30 days: > in bonded e-ptfe; - lymphocytes:- 7,30,90 and 180 days: in the control; macrophages:- 7,30 and 60 days: > in silicone \& bonded e-ptfe; 180 days > in silicone; fibroblasts: - 7,30 and 90 days: > in silicone and bonded e-ptfe; 180 days: > in bonded e-ptfe; vascular volume - 7,60,90 and 180 days: > in silicone and bonded e-ptfe; 30 days: > in bonded e-ptfe. Conclusions: The acute stage of the inflammatory response was more severe and irregular in the silicone implant; both the silicone implant and the silicone bonded with e-ptfe promoted chronic inflammatory reaction and weak foreign body inflammatory response. These reactions were greater in the silicone implant group.
\end{abstract}

Key words: Silicone Elastomers. Silicone Gels. Polytetrafluoroethylene. Rats, Wistar.

\section{RESUMO}

Objetivo: Comparar a reação inflamatória provocada pelo implante de silicone texturizado, com aquela causada por este recoberto com PTFE-E. Métodos: Foram utilizadas 150 ratas, divididos em três grupos igruais (controle, silicone e recoberto PTFE-E). Os grupos foram subdivididos em cinco subgrupos, ou seja, 7, 30, 60, 90 e 180 dias, de acordo com a data do segundo ato operatório. O tecido perimplante foi analisado histologicamente, por meio de técnica morfométrica, com contagem de neutrófilos, linfócitos, macrófagos, fibroblastos e capilares. Resultados: Comparação dos subgrupos 7, 30, 60, 90180 dias: - neutrófilos - silicone: > no subgrupo 7 dias; rec-ptfe: > nos subgrupos 7 e 30 dias; - linfócitos: silicone: > no subgrupo 7 e 180 dias; rec-ptfe: > no subgrupo 180 dias; - macrófagos: silicone: > no subgrupo 7 e 60 dias; rec-ptfe: > no subgrupo 7, 30 e 60 dias; - fibroblastos: silicone: > no subgrupo 30 e 60 dias; - volume vascular: silicone: $>$ no subrupo 7, 60 e 90 dias; rec-ptfe: > no subgrupo 7 dias . Comparação dos gurpos: - neutrófilos - 7 dias: > no silicone e rec-ptfe; 30 dias: > no rec-ptfe; - linfócitos - 7, 30, 90 e 180 dias: > no controle; - macrófagos - 7, 30 e 60 dias: > no silcone e rec-ptfe; 180 dias: > no silicone; - fibroblastos - 7, 30 e 90 dias: > no silicone e rec-ptfe; 180 dias: > no rec-ptfe; - volume vascular - 7, 60, 90 e 180 dias: > no silicone e rec-ptfe; 30 dias: > no rec-ptfe. Conclusões: A fase aguda da reação inflamatória foi mais intensa e irregular no implante de silicone; tanto o implante de silicone como o de silicone recoberto por ptfe-e induziram a reação inflamatória crônica e a fraca reação inflamatória tipo corpo estranho. Estas forram maiores no implante de silicone.

Descritores: Elastômeros de Silicone. Géis de Silicone. Politetrafluoretileno. Ratos Wistar. 


\section{Introduction}

The inflammatory response promoted by synthetic materials on receptor tissues depends on electrolyte surface activities and its stability to hydrolysis or to oxidation $^{(1)}$. The biological response to polymers is an inflammatory reaction, with collagen fiber deposits and maturation of fibrous connective tissue, around the implant. The fibrous capsule is flexible with smooth internal surface. A constrictive fibrosis termed capsular contracture can develop in some cases ${ }^{2}$. Even silicone, used in implants and considered chemically inert ${ }^{4}$, elicits an inflammatory reaction, with subsequent formation of a fibrotic capsule. Differences can occur in the capsular composition, depending on the material around the implant and the gel as well as the host's immunological response ${ }^{2}$. Capsular contracture corresponds to the consolidation and pain in the mammary region, and can distort the implant ${ }^{5}$. Varying in incidence, capsular contracture has been less severe in textured implants compared to smooth ones. Although textured implants have improved surgical results, capsular contracture continues without a definitive solution ${ }^{5}$. Many reasons have been proposed to explain this occurrence. Silicone molecules in the peri-implant tissue, have been advocated as the chief cause ${ }^{6,7}$. Another synthetic material used in Medicine is expanded polytetrafluoroethylene (e-ptfe $)^{1}$. It consists of nodules linked to flexible fibers of the material, forming a microporous structure. Prior studies that have employed e-ptfe, have exhibited a mildly severe inflammatory response to this material ${ }^{9}$. In the continuous search for new materials that promote minor inflammatory reaction in the host, thereby reducing possible formation of the fibrous capsule has led to the comparative study of the inflammatory response of textured silicone implants compared to those bonded with e-ptfe.

\section{Methods}

One hundred and fifty female rats (Rattus norvegicus albinos), weighing 200 g. were distributed into three groups: control, silicone and bonded e-ptfe group. Each group was then subdivided into five groups. These subgroups defined the dates in which the animals were reoperated to remove the specimens, i.e., implants and peri-implant tissues, on days 7,30,60,90,180 after insertion of the implants. The silicone implant was rounded, contained $2 \mathrm{~cm}^{3}$ volume of silicone gel, and covered by textured silicone with porosity ranging from 100 to $500 \mu \mathrm{m}$ and $2.2 \mathrm{~cm}$ diameter. The implant bonded with e-ptfe was similar but covered by a tube of e-ptfe with porosity of $30 \mu \mathrm{m}$ and $2.5 \mathrm{~cm}$ diameter. A $2.5 \mathrm{~cm}$ longitudinal incision was used to insert the implant in the animal's back, undermining the pocket below the panniculus carnosus muscle, in the animals of the silicone and bonded e-ptfe groups respectively. Closure was realized with 5-0 monofilament nylon. After the predetermined days, the animals underwent a new surgical procedure, with resection of the region that included the implant, from the skin to the deep muscles with margins of $0.5 \mathrm{~cm}$ on each side. Specimens were cut $6 \mu \mathrm{m}$ thick and stained with hematoxylin-eosin (H.E.). An optic microscope with $10 \mathrm{X}$ enlargment eyepiece was utilized, integrated grid with 25 squares and lense with $40 X$ enlargment. Eight fields were counted in the response tissue, with 25 spots each, that is, four fields in each surface, a total of 200 spots analyzed on each slide. The fields were all tangential to the material. The proportion of neutrophils, lymphocytes, macrophages, fibroblasts and giant cells were defined in relation to the total number of cells and the representative ratio of the vascular volume in relation to the capillaries. The Kruskal-Wallis variance analysis was applied for the statistical analysis. When a significant difference was detected, it was complemented by the multiple comparisons test. The level of rejection of the null hypothesis was set at 0.05 . The statistically significant values were indicated with a darker line and its comparison in a lighter one.

\section{Results}

\section{Percentage of neutrophils}

The comparison of subgroups 7, 30, 60, 90, 180 days, in the silicone group, showed a statistically significant difference in regard to the number of neutrophils among the 7 day subgroup and the 30 and 180 days subgroups $(p<0.01)$. In the bonded e-ptfe group, the comparison of subgroups showed a significant difference among the 7 and 30 days subgroups, compared to the 90 and 180 days subgroups $(\mathrm{p}<0.01)$. The control group did not show a significant difference (Figure 1).

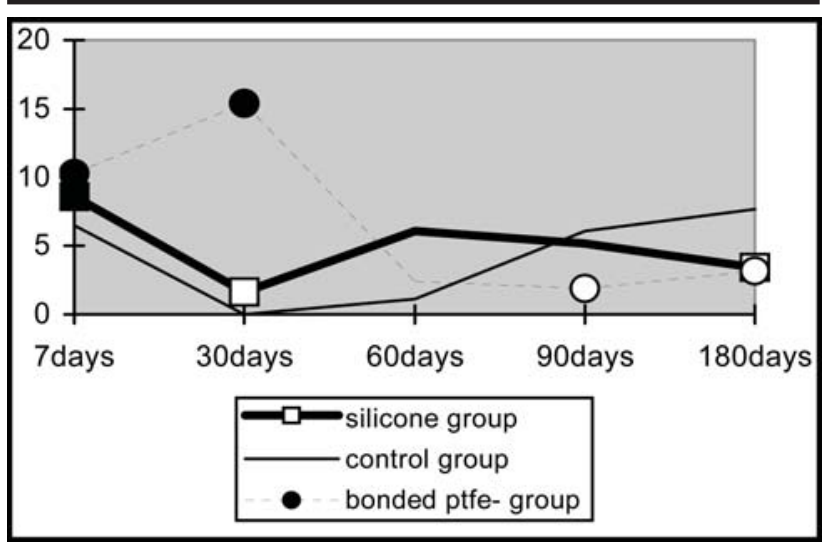

FIGURE 1 - Neutrophils. Comparison among subgroups (7, 30, 60, 90 and 180 days), of each group separately. The significant value is indicated with a dark line and the comparison in a light one 
Comparison among the silicone, bonded e-ptfe and control groups in the 7 days subgroup, displayed a statistically significant major number of neutrophils in the silicone and bonded e-ptfe, groups compared to the control group $(\mathrm{p}<0.01)$. In the 30 days subgroup, the comparison revealed a statistically significant major number of neutrophils among the bonded e-ptfe group and the silicone group $(\mathrm{p}<0.001)$. No significant difference was observed in the comparison of the other subgroups (Figure 2).

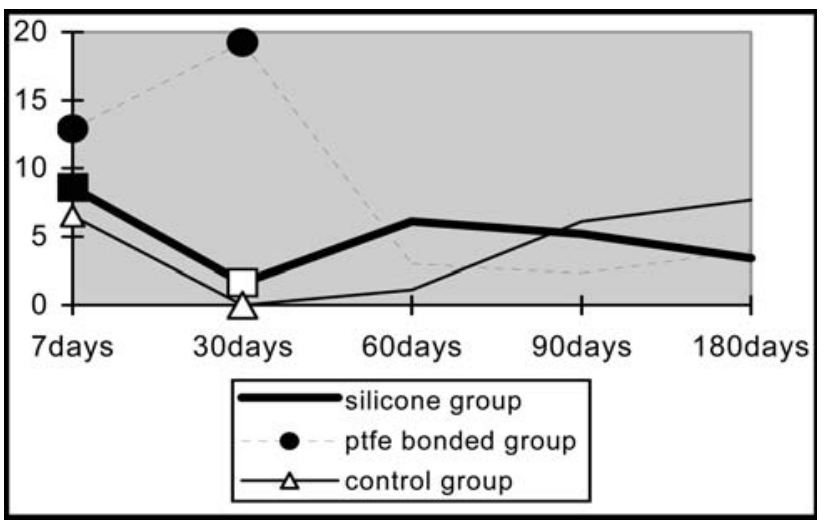

FIGURE 2 - Neutrophils. Comparison among the silicone, bonded e-ptfe and control groups, separately in each subgroup (7, 30, 60, 90 and 180 days). The significant value is indicated with a dark line and the comparison in a light one

\section{Percentage of lymphocytes}

Comparison among subgroups (7, 30, 60, 90, 180 days), in the silicone group showed a statistically significant major number of lymphocytes in the 7 and 180 days subgroup, compared to the 30,60,90 days subgroups $(\mathrm{p}<0.02)$. In the bonded e-ptfe group, comparison of the subgroups displayed a significant major number of lymphocytes in the 180 days subgroup, compared to the 30 days subgroup $(p<0.01)$. No significant difference was observed in the control group (Figure 3). Comparison among the silicone, bonded eptfe and control groups in subgroups 7,30, and 90 days, showed a statistically significant major number of lymphocytes in the control group compared to the silicone and bonded e-ptfe $(\mathrm{p}<0.01)$. Comparison of the 180 days subgroups indicated a statistically significant major number of lymphocytes among the control and the silicone groups $(\mathrm{p}<0.05)$. No significant difference was observed in the comparison of the groups, in the 60 days subgroups (Figure 4).

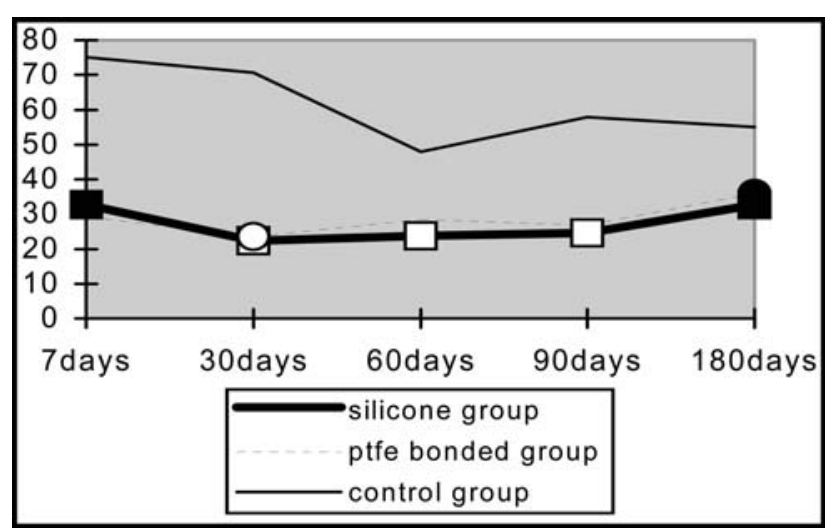

FIGURE 3 - Lynphocytes. Comparison among subgroups (7, 30, 60, 90 and 180 days), of each group separately. The significant value is indicated with a dark line and the comparison in a light one

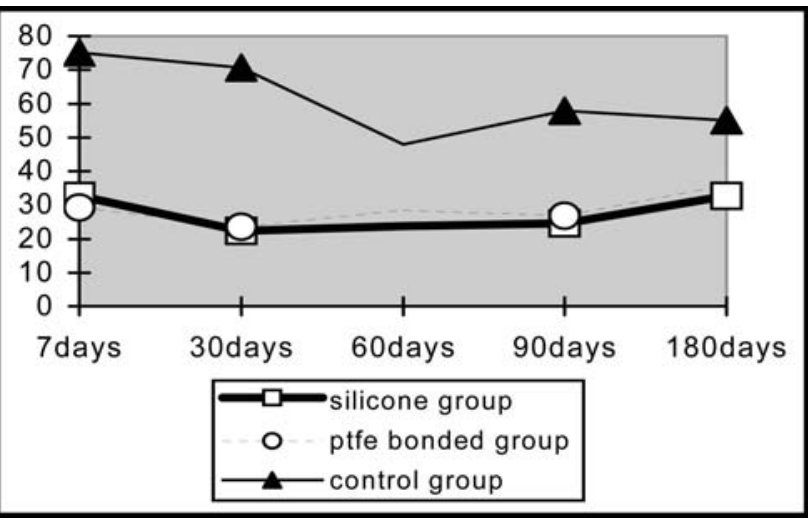

FIGURE 4 - Lynphocytes. Comparison among the silicone, bonded e-pfte and control groups separately in each subgroup (7, 30, 60, 90 and 180 days). The significant value is shown with a dark line and the comparison in a light one

\section{Percentage of macrophages}

Comparison among subgroups (7, 30, 60, 90, 180 days) in the silicone group, displayed a statistically significant major number of macrophages in the 7 and 60 days subgroups compared to the 90 days subgroups $((p<0.05)$. In the bonded e-ptfe group comparison of the subgroups showed a significant major number of lymphocytes among the 7,30 and 60 days subgroups compared to the 180 days subgroup $(\mathrm{p}<0.01)$. No significant difference was observed in the control group (Figure 5). Comparison among the silicone, bonded eptfe and control groups in the 7,30 and 60 days subgroups showed a statistically significant major number of macrophages in the silicone and bonded eptfe groups compared to the control group $(\mathrm{p}<0.01)$. Comparison of the 180 days subgroup, showed a significant major number of macrophages among the 
silicone group, compared to the bonded e-ptfe and control groups $(\mathrm{p}<0.05)$. No significant difference was observed in comparison of the groups, in the 90 days subgroup (Figure 6).

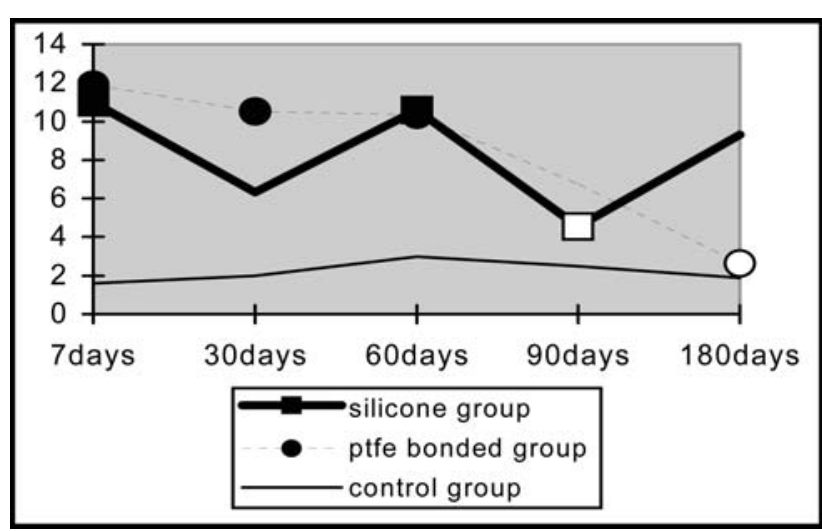

FIGURE 5 - Macrophages. Comparison among subgroups (7, 30, 60, 90 and 180 days), in each group separately. The significant value is indicated with a dark line and the comparison in a light one

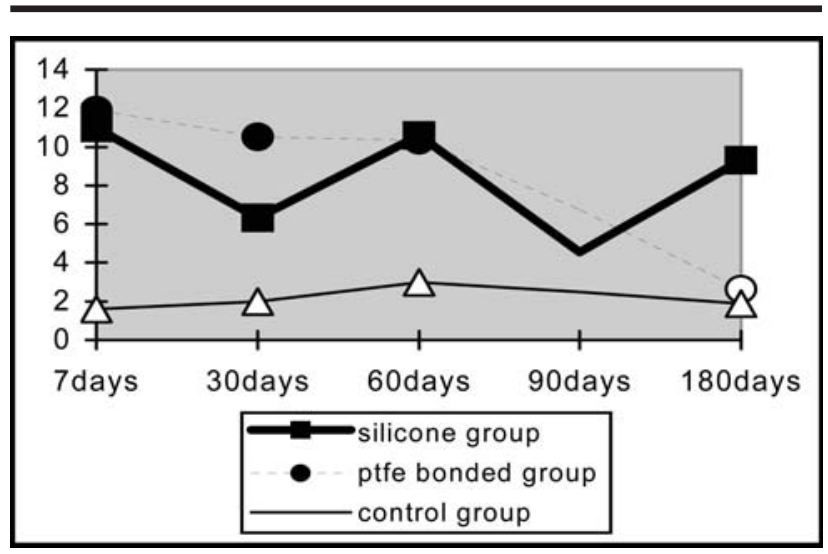

FIGURE 6 - Macrophages. Comparison among the silicone, bonded e-ptfe and control groups, separately in each subgroup (7, 30, 60, 90 and 180 days). The significant value is indicated with a dark line and its comparison in a light one

\section{Percentage of giant cells}

Comparison among subgroups and groups did not demonstrate a statistically significant difference.

\section{Percentage of fibroblasts}

Comparison among subgroups in the silicone group displayed a statistically significant major number of fibroblasts in subgroups 30 and 90 days, compared to the 180 days subgroups $(\mathrm{p}<0.01)$. No statistically significant difference was observed in the bonded e-ptfe group (Figure 7). In the control group, the comparison of the subgroups displayed a significant major number of fibroblasts in the 60 days subgroups, compared to the 30 days subgroups $(\mathrm{p}<0.01)$. Comparison among the silicone, bonded e-ptfe and control groups in subgroup 7 ( $<<0.01), 30(\mathrm{p}<0.001)$ and 90 days $(\mathrm{p}<0.02)$, displayed a statistically significant major number of fibroblasts in the silicone and bonded e-ptfe groups compared to the control group. In the 180 days subgroup, a statistically significant major number of macrophages was observed in the bonded e-ptfe group, compared to the control $(p<0.01)$. No significant difference was noticed in comparison of the groups with the 60 days subgroup (Figure 8).

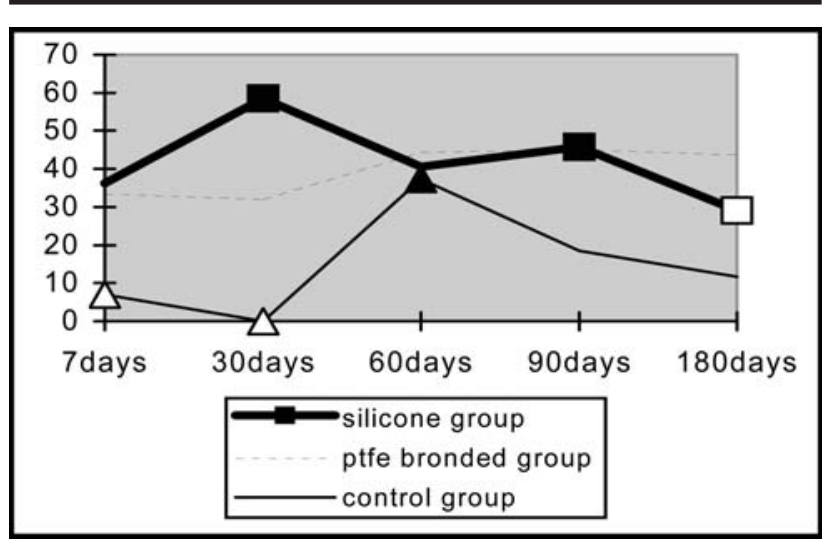

FIGURE 7 - Fibroblasts. Comparison among the subgroups, of each group separately. The significant value is indicated with a dark line and the comparison in a light one

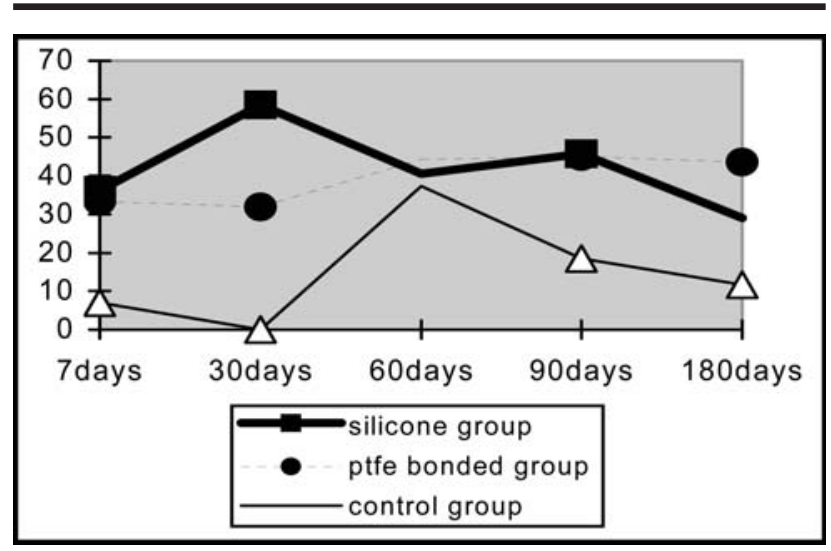

FIGURE 8 - Fibroblasts. Comparison of silicone, bonded e-ptfe and control groups, separately in each subgroup (7, 30, 60, 90, 180 days). The significant value is indicated with a dark line and the comparison in a light one

\section{Vascular volume - capillaries}

The comparison between subgroups (7, 30, 60, 90, 180 days) in the silicone group, showed a statistically significant major number of capillaries in the 7 days subgroup, compared to subgroups 30 and 180 days $(\mathrm{p}<0.001)$ and also in subgroups 60 and 90 days, 
compared to the 30 days subgroup. In the bonded e-ptfe group a statistically significant major number was present in the 7 days subgroup compared to 60 and 180 days $(\mathrm{p}<0.001)$ and also in the 30 days subgroup, compared to the 180 days. No statistical difference was observed in the control group (Figures 9 and 10). Comparison among the silicone, bonded e-ptfe and control groups in subgroups (7,60,90,180 days), displayed a statistically significant major number of capillaries in the silicone and bonded e-ptfe groups compared to the control group $(\mathrm{p}<0.001)$. The 30 days subgroup, compared to the group showed a statistically significant major number of capillaries in the bonded eptfe group compared to the silicone and control groups $(\mathrm{p}<0.01)$ (Figure 11).

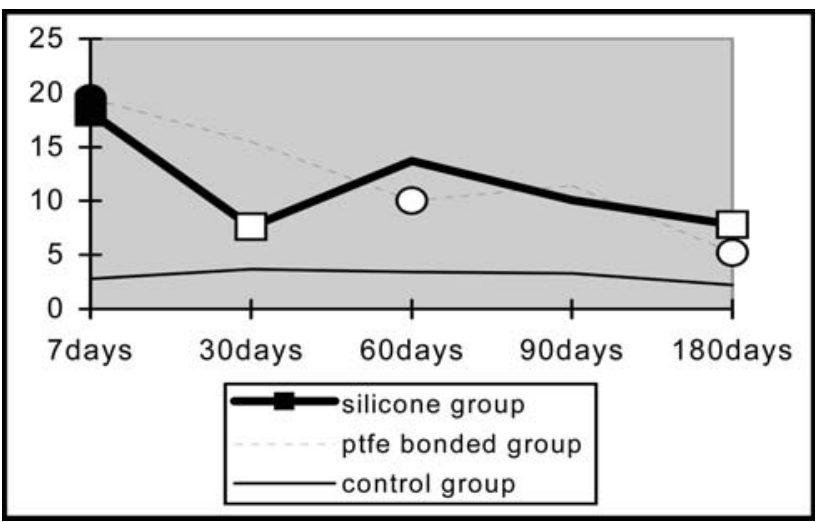

FIGURE 9 - Vascular volume. Comparison between subgroups (7, 30, 60, 90, 180 days) of each group separately. The significant value is indicated with a dark line and its comparison in a light one

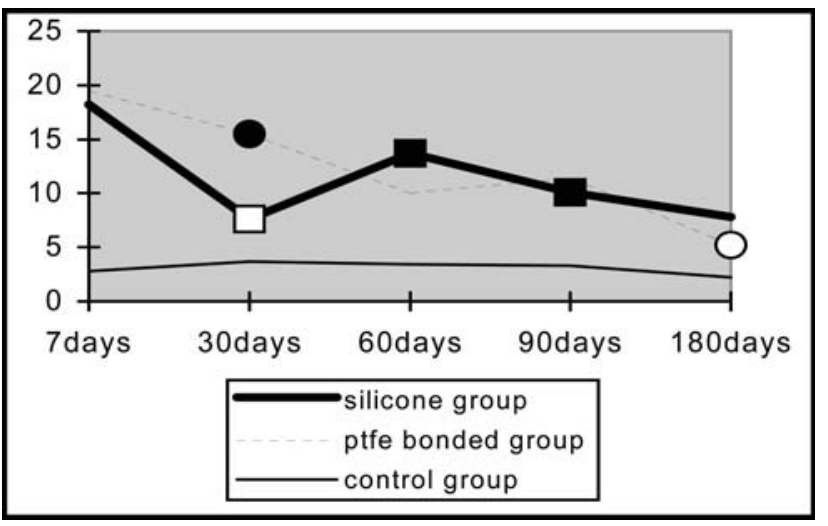

FIGURE 10 - Vascular volume. Comparison among subgroups (7, 30, 60, 90, 180 days) of each group separately. The significant value is indicated with a dark line and its comparison in a light one

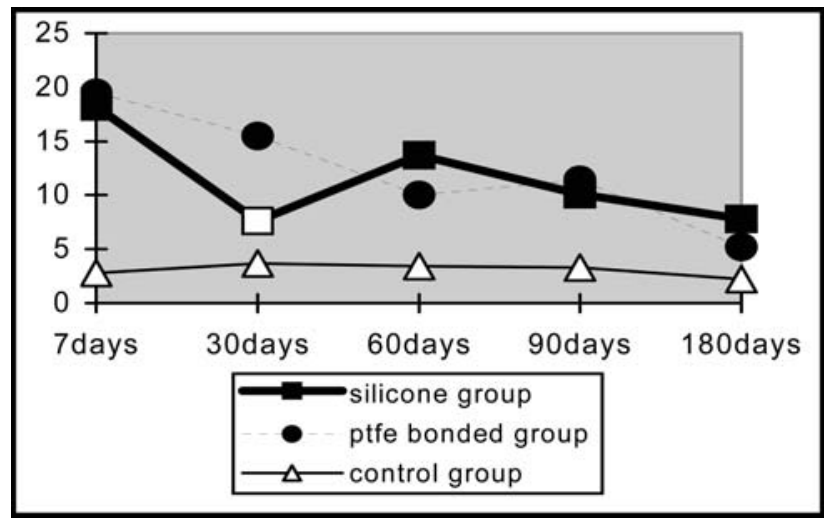

FIGURE 11 - Vascular volume. Comparison among the silicone, bonded e-ptfe and control groups in each subgroup (7, 30, 60, 90, 180 days), separately. The significant value is indicated with a dark color and its comparison in a light one

\section{Discussion}

The original silicone implant has undergone various alterations, with the objective of reducing its inflammatory reaction. These modifications occur not only in its fluid content in an attempt to prevent bleeding, but also around it, modifying its surface characteristics or the number of its layers. The response of host tissue to silicone implants has been the subject of numerous studies, since it can vary from the formation of a thin clinically unnoticeable capsule, to a thick, contracted one ${ }^{10}$. One of the most significant changes realized in smooth silicone implants was its textured surface ${ }^{11}$. Based on the search for other alternatives, it was decided to study the e-ptfe bonded to the textured silicone implant, because of other studies demonstrating the mild reaction of this material on host tissue ${ }^{2}$. An experimental study by Kafejian et al. ${ }^{9}$, compared tissue reactions to a fragment of smooth and rigid silicone implant and to a specimen of e-ptfe and evaluated 3,7 and 30 days after implantation using morphologic and morphometric analysis. Using electron microscopy Krause et al. ${ }^{12}$, analyzed the inflammatory response to silicone and eptfe implants, indirectly, over a two to seven day period, by quantification of activated interleukin-1, adhering to the surface of macrophages. The experimental study of Berman et al. ${ }^{13}$ idealized synthetic material of mixed origin, in which e-ptfe was bonded to smooth silicone and compared histologically with cartilage, supramid and silicone. Nonetheless, there are no clinical or experimental studies, comparing silicone to e-ptfe, bonded to silicone gel implants. Therefore, we proceeded to analyze the inflammatory response on rats caused by silicone gel implant covered by textured silicone and silicone gel implant covered by e-ptfe bonded to textured silicone. Concerning the 
inflammatory response itself, in brief it is a local reaction of the tissues to an aggression, which evolves qualitatively in a relatively stereotyped manner. After the aggression, an acute inflammatory response sets in, with vascular exudative phenomena, and predominance of neutrophils, lasting for about three days and followed by repair. When the aggressor agent is not removed and the acute inflammatory reaction lasts longer because of this, the response becomes chronic. In addition to the time element, it will represent a different physiopathogenic process, characterized by mononuclear cells in the tissue ${ }^{14}$. This accumulation of neutrophils is one of the most important features of the acute inflammatory reaction and increases at the onset of the process, eventually decreasing, giving way to other components that characterize the reconstructive stage ${ }^{14}$. It is possible to verify during the process, in the silicone group that a significant reduction in the number of neutrophils has occurred, concurring with the findings of Batra et al. ${ }^{15}$. This group experimentally analyzed silicone implants with various types of elastomers. The increased number of neutrophils noted during the acute inflammatory reaction, is also related to the operative trauma, as a characteristic of the healing response ${ }^{16,17}$. Although a non-significant increase had occurred in the number of neutrophils in subgroups 7 and 30 days, in the bonded e-ptfe group, a significant reduction was seen in regard to the 90 and 180 days periods, leading to resolution of the acute inflammatory response. It should be emphasized that the increase among subgroup 7 and 30 days, occurred because the acute inflammatory reaction continued in three of the ten animals. This was probably caused by contamination. When statistically analyzed, the increase in neutrophils observed in the 30 days subgroup, in calculation of averages, demonstrated a contradiction in the analysis of the process. Nevertheless, upon isolating this data, and using the mean, we observed a real trend that is the reduction of the number of neutrophils, corresponding to resolution of the inflammatory process. Even though limited to 30 days evolution, the results of Kafejian et al. ${ }^{9}$ and Haddad-Filho et al. ${ }^{18}$, the latter, in a comparative study between e-ptfe and bovine pericardium, confirmed the results obtained. When the silicone, bonded e-ptfe and control groups were compared, in the 7 days subgroup, a significant increase was noted in the number of neutrophils in the two-implant groups compared to the control group. In comparing the 30 days subgroups, their comparison displayed a significant difference regarding e-ptfe, in relation to the silicone and control groups, probably due to the contamination previously mentioned. This result permits us to conclude that the materials influence the inflammatory/repair process, in the same manner described by Guidugli-Neto ${ }^{19}$. The lymphocytes delineate cells of the histological profile of the chronic inflammatory reaction, and are rarely present in the acute inflammatory reaction, generally increasing progressively and accompanied by macrophages and granulation tissue. These cells act upon agents in which the neutrofiles are incapable of acting. The silicone group, demonstrated a significant reduction among the $7,30,60$ and 90 day subgroups. However, starting at 30 days, with the number of lymphocytes already lower, a small increase occurred in the other subgroups. These subgroups compared to the 180 days subgroup, displayed statistically significant differences, with chronicity of the inflammatory reaction. This probably occurred due to the presence of a foreign body reaction. Analysis of the average number of lymphocytes confirmed the averages of the results, i.e., chronicity of the inflammatory response was established. Batra et al. ${ }^{15}$, observed oscillation regarding the number of lymphocytes, in relation to textured silicone, however, they emphasized the permanence of this histological variable up to the end of the experiment, confirming the hypothesis of chronicity of the inflammatory reaction. The bonded e-ptfe group also displayed a tendency to chronicity of the inflammatory reaction during the periods. However, among the 7 and 30 day subgroups, the number of lymphocytes decreased, concurring with the findings of Kafejian et al. ${ }^{9}$ and Haddad-Filho et al. ${ }^{18}$, noted an increase in lymphocytes during the periods, which is contrary to what was observed in the present study, nevertheless, confirming the chronicity of the acute inflammatory reaction. The presence of macrophages also confirms the chronicity of the inflammatory reaction. The necessity of eliminating agents during the repair process, that the neutrophils could not eliminate, due to their size, will be eliminated by the macrophages ${ }^{17,20}$. The silicone group exhibited a relative maintenance of macrophages compared to the 7 and 180 day groups, with oscillations occurring in the $30,60,90$ day groups. It was significant in the 7 and 60 day subgroups, compared to the 90 day subgroup. Utilizing textured silicone gel implants Smahel et al. ${ }^{21}$, observed the presence of macrophages on histological examination, at 30 days. A comparative experimental study by Bern et al. ${ }^{22}$ of the biophysical and histological properties of the capsules formed after three months by the saline filled smooth and textured silicone implant, displayed an inflammatory reaction around the textured implant with many macrophages, among other inflammatory cells. Batra et al. ${ }^{15}$, in their study noticed macrophages from start to finish of the periods analyzed, this is one of the histological variables most frequently studied. The results of the evaluation of the chronicity of the acute inflammatory reaction analyzed in relation to macrophages, has led us to suggest a supposed tendency to chronicity coincident with the data observed. Regarding macrophages, in the bonded e-ptfe group, a statistically significant decrease was observed among subgroups 7, 30 and 60 days, compared to the 180 days 
subgroup. Nevertheless, both in the isolated and general analysis of the macrophages, in relation to the subgroups, even with a progressive reduction in their number, nevertheless, they demonstrated some degree of chronic inflammation, agreeing with the results of Kafejian et al. ${ }^{9}$. Berman et al. ${ }^{13}$, detected a mild foreign body reaction when analyzing the number of macrophages. Comparing the three groups (silicone, bonded e-ptfe and control), a significant reduction of macrophages was perceived in the 7,30 and 60 day subgroups of the two groups compared to the control group and in the 180 days subgroup of the silicone group compared to the eptfe and control groups. These findings permit us to conclude that the increase in macrophages must be stimulated by the presence of the material. The fibroblast the chief collagen-producing cell within the inflammatory process is responsible for production of organic material that the body will utilize for repair. Therefore, these cells would be expected to increase at the onset of repair and then decrease, either by maturation or because they are finally among the collagen fibers that they produced, making their visibility difficult ${ }^{23}$. In the silicone group, the number of fibroblasts increased at the start of repair and later decreased, and was significantly increased in the 30 and 90 day subgroups compared to the 180 days subgroup. Smahel et al. ${ }^{21}$, on the other hand, observed that fibroblast accumulation began at 90 days and that at 180 days their presence was conspicuous. Batra et al. ${ }^{15}$ described that a larger number of fibroblasts was present on the textured surfaces, but were also present on other surfaces studied (smooth and pillared). The number of young fibroblasts were now counted, without quantifying mature ones interspersed in the collagen fibers, observed at the end of repair in the present study. Comparison of subgroups 7,30 and 90 days, showed a significant increase in fibroblasts in relation to the silicone and bonded e-ptfe groups when compared to the control. In the 180 days group a significant difference between the bonded e-ptfe and control group was shown, illustrating that the materials induce tissue repair. Capillaries were present in major quantity at the onset of the inflammatory stage, diminishing after repair. We noticed that in the chronic inflammatory response, they form the granulation tissue ${ }^{17}$. In the silicone 7 days subgroup, a statistically significant decrease in capillaries in relation to the 30 and 180 days subgroups was observed. Although oscillations occurred during the time periods, the reduction in capillaries corresponds to the expected result. Smahel et al. ${ }^{21}$, similarly described an increase in the number of capillaries during the study period when textured silicone was employed. In the e-ptfe group a significant decrease in capillaries was observed compared to the 7,60 and 180 days subgroups. Comparison of the groups, showed a statistically significant major number of capillaries for subgroups 7 ,
60, 90 and 180 days in the silicone group and for subgroups 7,30,60,90 and 180 days of the bonded e-ptfe group, compared to the control group. This data demonstrates resolution of the inflammatory-repair process and interference of materials on it. Haddad-Filho et al. ${ }^{18}$ observed similar results during the 30 day period. Regarding the e-ptfe, Kafejian et al. ${ }^{9}$ observed an increase in capillaries at the end of 30 days. This data is in agreement, so long as we attribute the increase in capillaries to irregularity of the material and to vessels penetrating in it. When all the steps of tissue reaction to implants were analyzed, it was noted that during the entire process of acute and repair stage for both materials, from surgical manipulation to the end of the study, occurred in an interspersed and consecutive manner. It was also noticed that the acute inflammatory reaction, characterized the initial stage of the study, followed by chronic reaction of non-specific patterns associated to proliferation of granulation tissue, culminating with formation of a fibrous capsule, varying in thickness around both implants. Regarding silicone, the findings of the chronic inflammatory reaction, confirm the results of Kossovski et al. ${ }^{24}$. The present study enables us to conclude that the inflammatory process, starting from the acute stage to the repair stage, for both implants, occurred by interspersion and consecutively, the acute inflammatory reaction was more severe and irregular when the silicone implant was used, both materials induce a chronic inflammatory reaction, which is more severe when the silicone implant is used, and, finally, both materials cause a weak foreign body inflammatory reaction that is more marked when a silicone implant is used. Later studies will be developed to confirm the viability of this implant bonding material in humans.

\section{Conclusions}

The acute stage of the inflammatory response was more severe and irregular in the silicone implant; both the silicone implant and the silicone bonded with e-ptfe promoted chronic inflammatory reaction and weak foreign body inflammatory response. These reactions were greater in the silicone implant group.

\section{References}

1. Lilla JA, Vistness LM. Long term study of reactions to various silicone breast implants in rabbits. Plast Reconstr Surg. 1976;57:637-49.

2. Holmes RE. Alloplastic implants. In: McCarthy JC. Plastic surgery. Philadelphia: W.B. Saunders; 1990. p.698-731.

3. Brown JB, Fryer MP, Randall P, Lu M. Silicones in plastic surgery. Plast Reconstr Surg. 1953;12:374-6. 
4. Le Vier RR, Harrison MC, Cook RR, Lane TH. What is silicone? Plast Reconstr Surg. 1993;92:163-7.

5. Asplund O, Gylbert L, Jurell G, Ward C. Textured or smooth implants for submuscular breast augmentation: a controlled study. Plast Reconstr Surg. 1996;97:1200-6.

6. Asplund O. Capsular contracture in silicone gel and saline filled breast implants after reconstrution. Plast Reconstr Surg. 1984;73:270-5.

7. Caffee HH. The influence of silicone bleed on capsular contracture. Ann Plast Surg. 1986;17:284-7.

8. Carpaneda CA. Inflammatory reaction and capsular contracture around smooth silicone implants. Aesth Plast Surg. 1997;2:110-4.

9. Kafejian AP, Haddad-FIilho D, Guidugli-Neto J, Goldenberg S. Estudo comparativo das reações teciduais à implantação do silicone e politetrafluoroetileno-expandido no dorso de ratos. Acta Cir Bras. 1997;12:182- 8.

10.Riefkhol R. Augmentation mammoplasty. In: Mccarthy JC. Plastic surgery. Philadelphia: W.B. Saunders; 1990. p.3879-96.

11. Spear LS, Elmarghy M, Hess C. Textured surface saline filled silicone breast implants for augmentation mammaplasty. Plast Reconstr Surg. 2000;105:1542-52.

12. Krause TJ, Robertson FM, Liesh JB, Wasserman AJ, Grecce RS. Differential production of interleukin 1 on the surface of biomaterials. Arch Surg. 1990;125:1158-60.

13. Berman M, Pearce WJ, Tinnin M. The use of goretex e-ptfe bonded to silicone rubber as an alloplastic implant material. Laryngoscope. 1986;96:480-3.

14. Majno G, Joris I. Introduction to inflammation. In: Majno G, Joris I. Cells, tissue, and disease: principles of general pathology. Massachusetts: Blackwell Science; 1996. p.291-317.

15. Batra M, Bernard S, Picha G. Histologic comparison of breast implant shells with smooth, foam and pillar microstructuring in a rat from 1 day to 6 months. Plast Reconstr Surg. 1995;95:354-63.

16. Majno G, Joris I. General effects of local injury and inflammation. In: Majno G, Joris I. Cells, tissue and disease: principles of general pathology. Massachusetts: Blackwell Science; 1996. p.487-96.

17. Guidugli-Neto J. Inflamação. In: Guidugli-Neto, J. Elementos de patologia geral. São Paulo: Livraria Santos Editora; 1997. p.63-91.

18. Haddad-Filho D. Estudo comparativo das reações teciduais ao implante de pericárdio bovino e à inclusão de politetrafluoroetileno expandido em ratos [Dissertação - Mestrado]. São Paulo: Universidade Federal de São Paulo São Paulo, Escola Paulista de Medicina; 1998.

19. Guidugli-Neto J. The effect of roentgen radiation on the capillary sprouts and superficial loops on granulation tissue: quantitative study of the vascular volume. Rev Odontol Univ São Paulo. 1987;1:6-8.

20. Majno G, Joris I. Chronic inflammation. In: Majo G, Joris I. Cells, tissue and disease: principles of general pathology. Massachusetts: Blackwell Science; 1996. p.430-63.

21. Smahel J, Hurwitz P, Hurwitz N. Soft tissue response to textured silicone implants in an animal experiment. Plast Reconstr Surg. 1993;92:474-9.

22. Bern S, Burd A, May JW. The biophysical and histologic properties of capsules formed by sooth and textured silicone implants in the rabbits. Plast Reconstr Surg. 1992;89:1037-42.

23. Majno G, Joris I. Wound healing. In: Majno G, Joris I. Cells, tissue and disease: principles of general pathology. Massachusetts: Blackwell Science; 1996. p.466-85.

24.Kossovsk N, Stassi J. A pathophysiological examination of the biophysics and bioreactivity of silicone breast implants. .Semin Arthritis Rheum. 1994;24:18-21.

\section{Correspondence:}

Douglas Haddad Filho

Rua Bom Pastor, 1238

04203-001 São Paulo - SP Brazil
Conflict of interest: none Financial source: none

Received: January 16, 2007 Review: February 14, 2007

Accepted: March 15, 2007

\section{How to cite this article}

Haddad Filho D, Zveibel DK, Alonso N, Gemperli R. Comparison between textured silicone implants and those bonded with expanded polytetrafluoroethylene in rats. Acta Cir Bras. [serial on the Internet] 2007 May-June;22(3). Available from URL: http://www.scielo.br/acb 